\title{
LETTER
}

\section{Cytomegalovirus infection monitored by quantitative real-time PCR in critically ill patients}

\author{
Julien Bordes ${ }^{* 1,2}$, Tiphaine Gaillard³, Jérôme Maslin³, Pierre Esnault², Philippe Goutorbe ${ }^{2}$ and Patrick Brisou²
}

Cytomegalovirus (CMV) reactivation has been widely documented in the past 10 years in critically ill patients [1]. Conversely, few data are available on burn patients despite experimental studies showing that these patients are predisposed to herpes virus infections [2]. To our knowledge, only two studies reported the incidence of CMV infection in burn patients using a modern technique, such as PCR, which has become the gold standard $[3,4]$. These two studies demonstrated a high rate of CMV reactivation, $55 \%$ and $71 \%$, respectively. Moreover, CMV reactivation in burn patients has been proven to be intense. Indeed, in the study of Bordes and colleagues [4], $67 \%$ of patients who reactivated CMV experienced viremia greater than 1,000 copies $/ \mathrm{ml}$, and $33 \%$ viremia greater than 10,000 copies $/ \mathrm{ml}$. These results may reflect the severe immunosuppression that characterizes thermally injured patients. Consequently, severe burn patients could be considered as a model for CMV reactivation in critically ill patients. However, the precise kinetics of CMV DNA load in these patients is still poorly documented. That is why we would like to briefly present data from longitudinal monitoring of CMV infection by real-time PCR (RT-PCR) in four severe burn patients during their ICU stay (Figure 1).

All the patients were CMV IgG seropositive on admission. They were monitored for CMV reactivation once to twice a week. Detection of CMV DNA in blood samples was performed by quantitative RT-PCR on whole blood. The patients' characteristics are described in Table 1. Patient 2 presented a CMV-associated hemophagocytic syndrome and was treated by ganciclovir for a duration of 21 days. DNAemia became undetectable in patients 3 and 4 spontaneously. These examples demonstrate that critically ill patients may experience several episodes of CMV reactivation during their ICU stay, and that CMV viral load can be very changeable. Furthermore, CMV viremia may be highly variable over a short period.

*Correspondence: bordes.julien@neuffr

'Teaching Military Sainte Anne Hospital, Department of Intensive Care and

Anesthesiology, BP20545, 83041 Toulon Cedex 9, France

Full list of author information is available at the end of the article
In our opinion, CMV reactivation in critically ill patients should be monitored with quantitative methods of detection, such as RT-PCR. Indeed, we hypothesize that the potential role of CMV on patient outcome is mostly due to the intensity of CMV reactivation rather than the CMV reactivation per se. That is why we suggest that studies aimed at determining the role of CMV reactivation as a contributor to outcome in critically ill patients should use quantitative methods of detection. Consequently, a CMV viremia threshold could be determined to guide preemptive therapy in these patients.

Written consent for publication was obtained from the patients or patients' relatives.

\section{Abbreviations}

$C M V$, cytomegalovirus; $P C R$, polymerase chain reaction; RT-PCR, real-time PCR.

\section{Competing interests}

The authors declare that they have no competing interests.

\section{Author details}

'Teaching Military Sainte Anne Hospital, Department of Intensive Care and Anesthesiology, BP20545, 83041 Toulon Cedex 9, France. 'Burn Center, Sainte Anne Hospital, BP20545, 83041 Toulon Cedex 9, France. 'Laboratory of Biology, Sainte Anne Hospital, BP20545, 83041 Toulon Cedex 9, France.

\section{Published: 18 March 2011}

\section{References}

1. Osawa R, Singh N: Cytomegalovirus infection in critically ill patients: a systematic review. Crit Care 2009, 13:R68.

2. Kobayashi M, Herndon DN, Pollard RB, Suzuki F: CD4+ contrasuppressor T cells improve the resistance of thermally injured mice infected with HSV. J Leukoc Biol 1995, 58:159-167.

3. Limaye AP, Kirby KA, Rubenfeld GD, Leisenring WM, Bulger EM, Neff MJ, Gibran NS, Huang ML, Santo Hayes TK, Corey L, Boeckh M: Cytomegalovirus reactivation in critically ill immunocompetent patients. JAMA 2008, 300:413-422.

4. Bordes J, Maslin J, Prunet B, d'Aranda E, Lacroix G, Goutorbe P, Dantzer E, Meaudre E: Cytomegalovirus infection in severe burn patients monitoring by real-time polymerase chain reaction: A prospective study. Burns 2011 [Epub ahead of print].

doi:10.1186/cc10066

Cite this article as: Bordes J, et al: Cytomegalovirus infection monitored by quantitative real-time PCR in critically ill patients. Critical Care 2011, 15:412. 


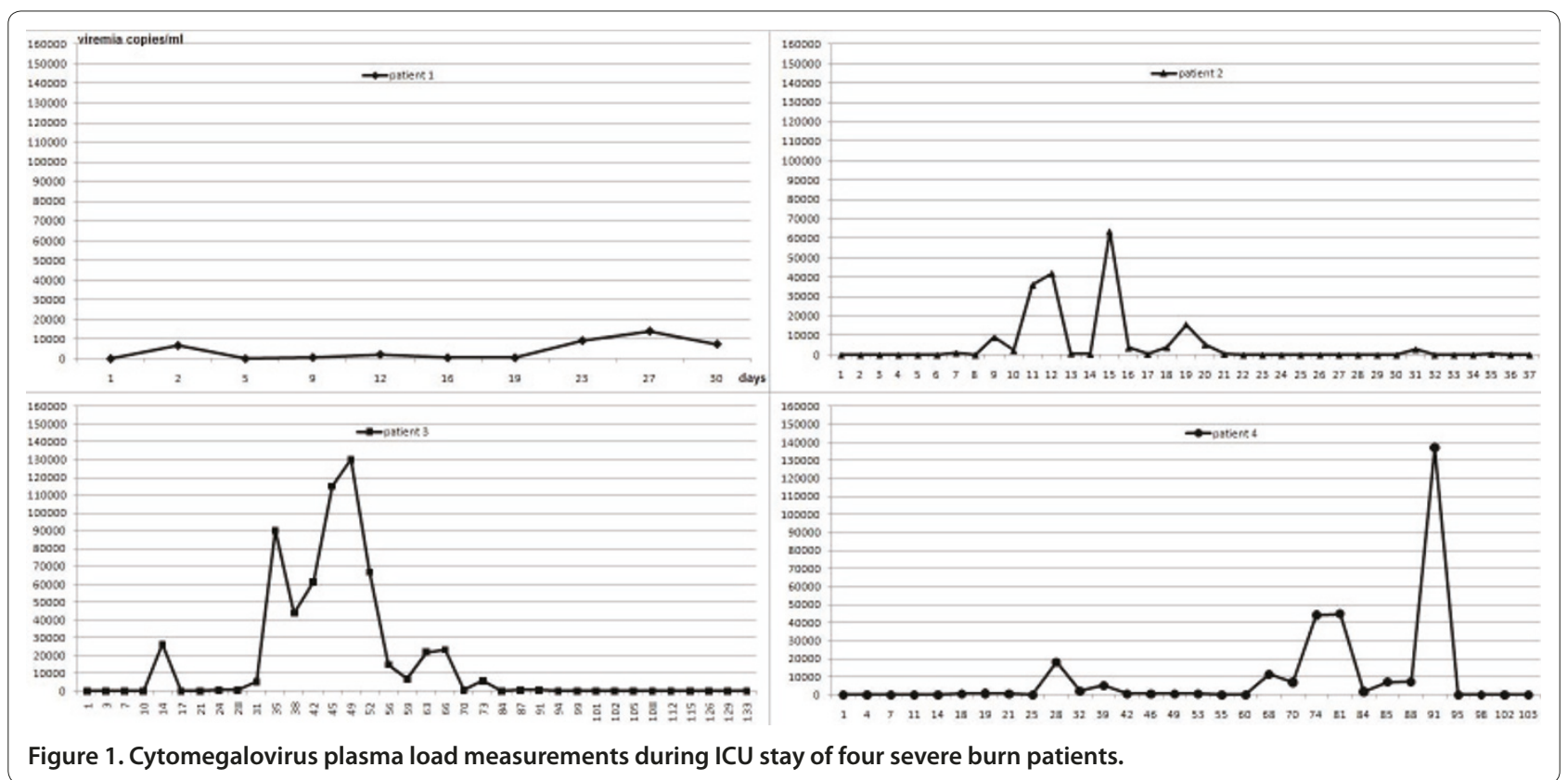

Table 1. Patient characteristics

\begin{tabular}{lccccccc}
\hline Patient & Age (years) & TBSA (\%) & DBSA (\%) & IGS 2 score & ICU stay (days) & Viremia peak $^{\text {a }}$ & Outcome \\
\hline 1 & 80 & 15 & 0 & 41 & 30 & 141,130 & Discharged from ICU \\
2 & 76 & 40 & 40 & 38 & 133 & 63,400 & Died in ICU \\
3 & 82 & 15 & 15 & 54 & 130,000 & Discharged from ICU \\
4 & 60 & 28 & 20 & 29 & 137,000 & Died in ICU \\
\hline
\end{tabular}

